\title{
Composição florística de florestas estacionais ribeirinhas no Estado de Mato Grosso do Sul, Brasil ${ }^{1}$
}

\author{
Vivian Ribeiro Baptista-Maria ${ }^{2,6}$, Ricardo Ribeiro Rodrigues ${ }^{3}$, Geraldo Damasceno Junior ${ }^{4}$, \\ Fabrício de Souza Maria ${ }^{5}$ e Vinicius Castro Souza ${ }^{3}$
}

Recebido em 24/09/2007. Aceito em 9/10/2008

\begin{abstract}
RESUMO - (Composição florística de florestas estacionais ribeirinhas no Estado de Mato Grosso do Sul, Brasil). O presente estudo teve como objetivos caracterizar a composição florística em dois trechos de floresta estacional semidecidual associada ao rio Formoso, Bonito, MS, e em três trechos de florestas estacionais deciduais e semideciduais associadas aos rios Salobra, Salobrinha e Perdido ocorrentes no Parque Nacional da Serra da Bodoquena (76.481 ha) - única unidade de Conservação Federal de Proteção Integral implantada no Estado de Mato Grosso do Sul. O levantamento florístico foi realizado mensalmente entre o período de outubro/2004 a março/2006, onde foram coletadas fanerógamas em fase reprodutiva (flores e frutos), através do método de tempo de avaliação. O levantamento florístico resultou em 56 famílias, 184 gêneros e 307 espécies. Do total das espécies, 68\% apresentaram hábito arbóreo, $17 \%$ arbustos, $14 \%$ foram lianas e apenas 1\% palmeiras. A família Fabaceae (Leguminosae), representada por 51 (16,6\%) espécies, foi a de maior riqueza. Os resultados obtidos neste trabalho contribuíram para o conhecimento da flora sul-mato-grossense e sua distribuição geográfica, reforçando a necessidade de conservação destas matas ribeirinhas e fornecendo subsídios para os planos de restauração das áreas degradadas do entorno da unidade de conservação e das áreas de proteção permanente (APP's) dos rios ocorrentes na região.
\end{abstract}

Palavras-chave: flora sul-mato-grossense, floresta estacional, Parque Nacional da Serra da Bodoquena

\begin{abstract}
Floristic composition of seasonal riparian forests in Mato Grosso do Sul State, Brazil). This study aimed to characterize the floristic composition in two stretches of seasonal semideciduous forest associated with the Formoso River, Bonito, Mato Grosso do Sul State, and in three stretches of seasonal deciduous and semideciduous forests associated with the Salobra, Salobrinha and Perdido rivers in Bodoquena Plateau National Park (76,481 ha) - the only Federal Conservation unit with Integral Protection in the state of Mato Grosso do Sul. The floristic survey was carried out monthly from October/2004 to March/2006, where flowering and fruiting phanerogams were collected by the method of evaluation time. The floristic survey resulted in 56 families, 184 genera and 307 species. Of the total number of species, $68 \%$ were trees, $17 \%$ shrubs, $14 \%$ lianas and only $1 \%$ palms. The Fabaceae family (Leguminosae), represented by 51 $(16.6 \%)$ species, was the most species-rich. These results increase our knowledge of the Mato Grosso do Sul flora and its geographic distribution, thus emphasizing the need for conservation of these riparian forests and providing subsidies for restoration projects of the degraded areas around the conservation unit and permanent protection areas (APPs) of regional rivers.
\end{abstract}

Key words: seasonal forest, flora, Bodoquena Plateau National Park

\section{Introdução}

As formações savânicas, variando de campos limpos até cerradões (Cole 1986; Ribeiro \& Walter 1998) predominam no Brasil Central compondo o bioma Cerrado em $65 \%$ do território. Porém, as formações florestais são expressivas mesmo cobrindo menor extensão. As florestas estacionais ribeirinhas apesar de estreitas, formam uma extensa malha dendrítica envolvendo os cursos d'água de modo que, mesmo ocupando apenas 5\% da área, contém 2.031 espécies de fanerógamas (Felfili et al. 2001a), representando 30\% da flora fanerogâmica do Brasil Central (Mendonça et al. 1998). Assim, a importância de conhecer estes ambientes

\footnotetext{
1 Parte da Tese de Doutorado da primeira Autora

2 Escola Superior de Agricultura "Luiz de Queiroz", Departamento de Ecologia Aplicada, Centro de Energia Nuclear Universidade de São Paulo, Piracicaba, SP, Brasil (endereço para correspondência: Rua 02 de Outubro 165, Vila Recreio, 79290-000 Bonito, MS, Brasil)

3 Universidade de São Paulo, Escola Superior de Agricultura “Luiz de Queiroz”, Departamento de Ciências Biológicas, C. Postal 09, 13418-900 Piracicaba, SP, Brasil

4 Universidade Federal de Mato Grosso do Sul, Departamento de Biologia, C. Postal 549, 79070-900 Campo Grande, MS, Brasil

5 Instituto de Ensino Superior da Funlec, Av. Cel. Rebuá s.n., Vila Recreio, 79290-000 Bonito, MS, Brasil

6 Autor para correspondência: vrbmaria@gmail.com
} 
e entender os mecanismos de conservação, composição, estrutura, diversidade e ecologia das espécies vegetais e a sua relação com os fragmentos a que estão ligados.

As informações resultantes de levantamentos florísticos (Oliveira Filho \& Ratter 1995) tem sido importantes para compreensão dos padrões biogeográficos da vegetação, determinando áreas prioritárias para a conservação e restauração. Os levantamentos estritamente florísticos permitem comparações relativamente simples e eficientes entre um grande número de áreas geograficamente próximas e/ou florísticamente parecidas (van den Berg \& Oliveira Filho 2000).

Entretanto, são poucos os estudos florísticos sobre as florestas decíduas e semidecíduas no Brasil Central (Felfili 2003; Marimon et al. 2001), em especial na Serra da Bodoquena, localizada na região sudoeste de Mato Grosso do Sul, onde encontra-se um dos últimos remanescentes de floresta estacional semidecidual e decidual de grande extensão, com qualidade preservada (Pott \& Pott 2003). As florestas estacionais encontradas nessa região, na sua grande maioria estão presentes nas margens dos rios ou topo de morros, porém mesmo protegidas por legislação específica, estas formações foram e continuam sendo drasticamente eliminadas em função da expansão pecuária e agrícola, e da exploração madeireira, destinadas ao uso civil e industrial (na forma de carvão). Desta forma, as constantes ameaças e a escassez de estudos sobre a flora da Serra da Bodoquena e áreas consideradas de entorno reforçam a necessidade urgente de levantamentos florísticos em trechos de matas ribeirinhas, visando subsidiar ações voltadas ao manejo, preservação e recomposição dessas formações (Battilani et al. 2005).

Neste contexto, este trabalho tem por objetivo estudar a composição florística em dois trechos de floresta estacional semidecidual associada ao rio Formoso, Bonito, MS, bem como em quatro trechos de florestas estacionais deciduais e semideciduais associadas aos rios Salobra, Salobrinha e Perdido ocorrentes no Parque Nacional da Serra da Bodoquena (76.481 ha), única unidade de Conservação Federal de Proteção Integral implantada no Estado de Mato Grosso do Sul, e que abriga amostras significativas de florestas estacionais ribeirinhas. Os resultados obtidos permitiram produzir uma lista de espécies vasculares existentes nas áreas amostradas, contribuindo assim para o maior conhecimento da flora sul-mato-grossense, sua distribuição geográfica e no fornecimento de subsídios para os planos de restauração das áreas degradadas do entorno da unidade de conservação e das áreas de proteção permanente (APP's) dos rios ocorrentes na região.

\section{Material e métodos}

Área de estudo - O estudo foi desenvolvido em duas unidades de relevo distintas, a Serra da Bodoquena, onde encontra-se inserido o Parque Nacional da Serra da Bodoquena e a Zona Serrana Oriental a leste da Serra da Bodoquena, a qual está inserida a Bacia Hidrográfica do rio Formoso $\left(21^{\circ}-21^{\circ} \mathrm{S}\right.$ e $\left.56^{\circ}-56^{\circ} \mathrm{W}\right)$. O clima da região é do tipo Tropical Chuvoso de Savana (Aw) segundo Köppen (1948). A precipitação média anual varia de 1.400 a $1.600 \mathrm{~mm}$, apresentando dois períodos distintos: um chuvoso (outubro a março) e outro seco (abril a setembro). As temperaturas médias anuais estão entre $22^{\circ}$ e $26^{\circ} \mathrm{C}$. De maio a agosto a temperatura média está abaixo de $20^{\circ} \mathrm{C}$ e em junho-julho pode ficar abaixo de $18{ }^{\circ} \mathrm{C}$. A média das máximas anuais fica entre $27^{\circ} \mathrm{e}$ $32{ }^{\circ} \mathrm{C}$, com máximas absolutas entre $35^{\circ}$ e $40^{\circ} \mathrm{C}$. As mínimas absolutas podem chegar a $0{ }^{\circ} \mathrm{C}$. A umidade relativa do ar é baixa, raramente atinge $80 \%$. De acordo com o sistema Brasileiro de Classificação de Solos (Embrapa 1999), na bacia do rio Formoso, predominam os solos do tipo Argissolos, de textura arenosa, média, profundos, monofásicos, não hidromórficos, apresentando fertilidade natural baixa e horizonte A moderado. No PARNA da Serra da Bodoquena há predominância de solos do tipo rendzina, caracterizados por serem pouco desenvolvidos, com horizonte A chernozênico sobre a rocha calcária ou sobre um horizonte $\mathrm{C}$ derivado desta. O Parque Nacional da Serra da Bodoquena é dividido em dois grandes blocos geomorfológicos com características distintas: um ao norte com área de 27.793 ha e outro ao sul, com 48.688 ha. Ao norte, onde a drenagem converge para o rio Salobra, as feições fluviais são mais marcantes do que as cársticas, havendo a ocorrência de rios entalhados (cânions), onde a borda ocidental da serra apresenta escarpas íngremes e reentrâncias profundas e estreitas. A vegetação é caracterizada pelo contato de fisionomias florestais e savânicas. Ao sul, as águas drenam principalmente para o rio Perdido, e as feições cársticas são mais comuns que as fluviais. Ambos os compartimentos apresentam calcários calcíticos e acredita-se que as diferenças entre eles sejam atribuídas ao maior soerguimento tectônico da parte norte (Sallun et al. 2004; Alvarenga et al. 1982). As coletas de materiais botânicos foram realizadas em seis propriedades rurais, sendo duas associadas ao rio Formoso, duas ao rio Perdido (fragmento sul do Parque), uma ao rio Salobrinha e uma ao rio Salobra, sendo os dois últimos situados no fragmento norte do Parque Nacional da Serra da Bodoquena (Fig. 1):

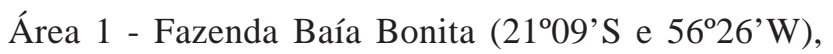
propriedade do Sr. Luiz Alberto Chemin e Nelson Izidoro 
Chemin Junior, localizada as margens do rio Formoso. Vegetação ribeirinha, composta por Floresta Estacional Semidecidual Ribeirinha (Rodrigues 2004).

Área 2 - Fazenda América $\left(21^{\circ} 14^{\prime} \mathrm{S}\right.$ e $\left.56^{\circ} 33^{\prime} \mathrm{W}\right)$, propriedade do Sr. Luiz de Brito, localizada as margens do rio Formoso. Vegetação ribeirinha, composta por Floresta Estacional Semidecidual Ribeirinha (Rodrigues 2004).

Área 3 - Fazenda Harmonia $\left(21^{\circ} 13^{\prime}\right.$ 'S e $\left.56^{\circ} 45^{\prime} \mathrm{W}\right)$, propriedade da Associação das Famílias para a Unificação e Paz Mundial, localizada as margens do rio Perdido.
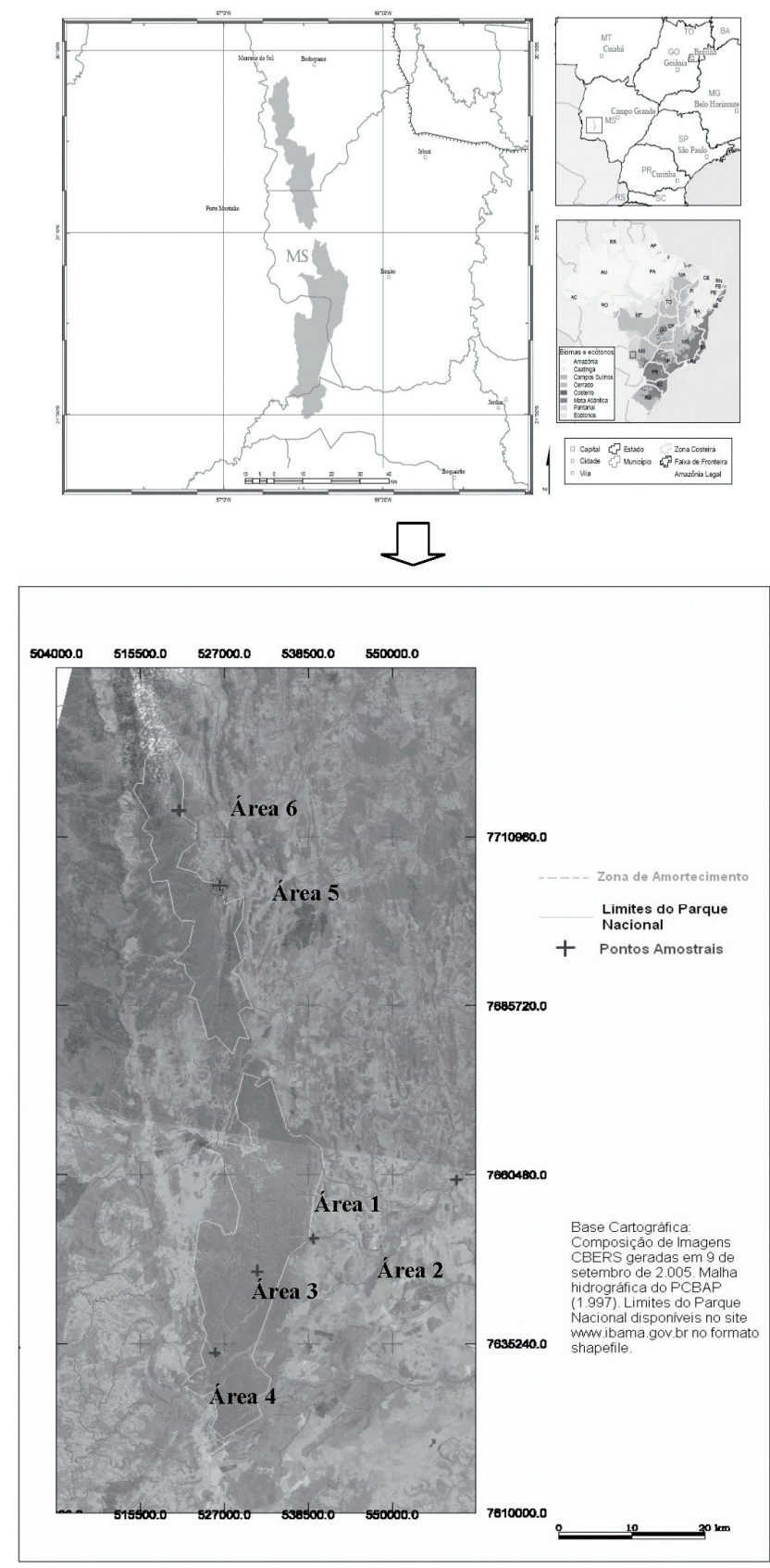

Figura 1. Mapa de localização do Parque Nacional da Serra da Bodoquena, MS, Brasil e localização dos pontos de amostragem.
Vegetação ribeirinha, composta por Floresta Estacional Decidual Ribeirinha (Rodrigues 2004).

Área 4 - Fazenda Campo Verde ( $21^{\circ} 18^{\prime}$ S e $\left.56^{\circ} 43^{\prime} \mathrm{W}\right)$, propriedade do Sr. Marcelo Barros, localizada as margens do rio Perdido. Vegetação ribeirinha, composta por Floresta Estacional Semidecidual Ribeirinha (Rodrigues 2004).

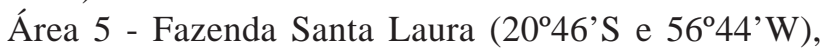
propriedade do Sr. Antônio Amado, localizada as margens do rio Salobra. Vegetação ribeirinha, composta por Floresta Estacional Semidecidual Ribeirinha (Rodrigues 2004).

Área 6 - Fazenda Rancho Branco (2040'S e 56² $46^{\prime} \mathrm{W}$ ), propriedade do IBAMA (desde 2006), localizada as margens do rio Salobrinha. Vegetação ribeirinha, composta por Floresta Estacional Semidecidual Ribeirinha (Rodrigues 2004).

Amostragem - O levantamento florístico foi realizado mensalmente entre o período de outubro/2004 a março/2006, nas florestas ribeirinhas ocorrentes no rio Formoso, Perdido, Salobra e Salobrinha. O método utilizado foi o tempo de avaliação, ou seja, cronometrando a amostragem em caminhadas previamente estabelecidas cortando todo o trecho florestal, até não aparecer novas espécies em 15 minutos de amostragem contínuas (Kotchetkoff 2003; Santin 1999). A suficiência da amostragem foi verificada através da curva do coletor, com base no número acumulado de novas ocorrências em função dos meses de coleta. O mesmo número de horas amostrais foram utilizadas em todas as áreas em estudo. Durante as caminhadas de coleta, foram amostradas espécies em fase reprodutiva e predominantemente de porte arbustivo-arbóreo, lianas e palmeiras. Houve repetição de coletas de uma mesma espécie quando esta foi encontrada em diferentes fases reprodutivas (com flores ou frutos). Foram percorridas trilhas no interior e bordas das florestas visando à amostragem da vegetação em diferentes fases sucessionais. A coleta do material botânico foi realizada com o auxílio de uma tesoura de poda alta, adaptada a duas varas ajustáveis de alumínio, chegando a atingir $8 \mathrm{~m}$ de altura. As árvores de maior porte foram escaladas com esporas por profissional habilitado. Durante as coletas com podão e espora o cronômetro foi zerado, para não interferir no método utilizado. O material coletado de cada indivíduo foi agrupado com fita crepe, numerado e transportado em sacos plásticos. Posteriormente, o material foi prensado e herborizado pelos procedimentos usuais e identificado com auxilio de literatura especializada e comparações com exsicatas existentes em herbários (ESA, CGMS e COR) ou ainda a consulta a especialistas. Os espécimes foram agrupados em famílias de acordo com o sistema APG II (APG II 2003; Souza \& Lorenzi 
2005). Os autores das espécies foram confirmados nas bases de dados disponíveis na internet (Missouri Botanical Garden 2007). Após a identificação, o material foi incorporado ao herbário da Escola Superior de Agricultura "Luiz de Queiroz"/USP (ESA), com duplicatas na Universidade Federal de Mato Grosso do Sul/UFMS (CGMS). As espécies foram classificadas de acordo com o hábito, visando mostrar a distribuição da riqueza florística da área de estudo. Para isto foram consideradas as definições apresentadas em Dislich (1998): i) Árvore - Planta lenhosa que ramifica acima de $0,5 \mathrm{~m}$; ii) Arbusto - Planta pequena, de base lenhosa, que ramifica abaixo de 0,5 m de altura; iii) Palmeira - Planta que apresenta caule do tipo estipe, pertencentes à família Arecaceae; e iv) Liana - toda planta de hábito escandente de forma ampla, tanto herbácea quanto lenhosa. A similaridade florística entre as áreas foi verificada através dos índices qualitativos de Jaccard (1912) e Sørensen (1948) descritos em van Tongeren (1995). Para verificar a similaridade estrutural entre as áreas utilizou-se a Análise de Correspondência (CA), que realiza a ordenação das espécies e das áreas de amostragem simultaneamente, permitindo o exame das relações entre ambas numa única análise.

\section{Resultados e discussão}

O levantamento florístico das áreas florestais ribeirinhas presentes no Parque Nacional da Serra da Bodoquena e no rio Formoso resultou em 609 coletas, distribuídas em 56 famílias, 184 gêneros e 307 espécies (Tab. 1). A curva do coletor mostrou uma tendência à estabilização de acréscimo de espécies a cada coleta realizada nas áreas amostradas (Fig. 2). As dez famílias de maior riqueza florística (Fig. 3) contribuíram com $53,09 \%$ das espécies amostradas, e as demais 46 famílias com 46,91\% das espécies. A família Fabaceae, representada por 51 espécies, foi a de maior riqueza, perfazendo $16,61 \%$ do total de espécies registrada. Dentro desta família, obtivemos 19 espécies para subfamília Mimosoideae (6,19\%), 14 espécies para Faboideae (4,56\%), 18 para Caesalpinioideae $(5,85 \%)$. Seguida tivemos a família Myrtaceae, representada por 21 espécies (6,84\%), Sapindaceae e Euphorbiaceae que representaram 14 espécies cada (4,56\%), Moraceae representada por 13 espécies (4,23\%), Meliaceae com 12 espécies $(3,90 \%)$, Rutaceae e Rubiaceae com dez espécies $(3,25 \%)$ e por fim com 09 espécies cada foram registradas as famílias Bignoniaceae e Malvaceae $(2,93 \%)$. Onze famílias $(19,64 \%)$ foram representadas por somente uma espécie. Estes resultados são semelhantes aos obtidos por Battilani et al. (2005), Felfili et al. (2001b), Rodrigues \& Nave (2004) e Salis et al.
(1994) que citam as famílias Fabaceae, Myrtaceae, Meliaceae, e Rutaceae como as mais representativas em número de espécies arbustivo-arbóreas nas matas ribeirinha. A família Myrtaceae sempre contribuiu com muitas espécies nas matas ribeirinhas (Nunes et al. 2003). Dados evidenciam a importância das Fabaceae nas formações vegetacionais do Mato Grosso do Sul e sudeste do Brasil. Nas florestas estacionais semideciduas submontanas e ribeirinhas do Mato Grosso do Sul, as Fabaceae são citadas como uma família que apresenta maior riqueza em Sciamarelli (2005) e Romagnolo \& Souza (2000). O mesmo foi verificado para as florestas estacionais semideciduas do interior de São Paulo (Cavassan et al. 1984; Bertoni \& Martins 1987; Pagano \& Leitão Filho 1987; Rodrigues et al. 1989), nas florestas ribeirinhas da serra da Bodoquena (Damasceno-Junior et al. 2000) e por Pagotto \& Souza (2006) no inventário biológico do Complexo Aporé-Sucuriú/MS. Leitão Filho (1982), descrevendo a estrutura das matas ciliares, relata que nos estratos superiores existe clara dominância de Fabaceae, principalmente por Mimosoideae. Nota-se o predomínio de famílias constituídas predominantemente por espécies de hábito arbóreo (Tab. 2). Nas florestas estacionais ribeirinhas estudadas, as espécies arbóreas representaram $68 \%$ do total de espécies amostradas, os arbustos totalizaram $17 \%$, as lianas somaram $14 \%$, e as palmeiras apenas $1 \%$. O destaque de lianas na comunidade deve ser ainda maior do que foi constatado neste estudo, considerando que as lianas estão subamostradas, pois a grande dificuldade de coleta e visualização destas formas de vida em áreas com dossel em torno de $16 \mathrm{~m}$. Os gêneros que mais contribuíram com o número de espécies foram Eugenia, com 11, Ficus com 10, Trichilia com oito, Piper com sete espécies, seguidos por Aspidosperma, Machaerium e Inga representados por cinco espécies cada. Ao longo de toda a área estudada foi observada elevada abundância de Attalea phalerata Mart. ex Spreng. (Arecaceae) e freqüentes agrupamentos de Guadua cf. chacoensis (Rojas) Londõno \& P.M. Peterson (Poaceae). Estas espécies predominam em determinados locais devido principalmente as características edáficas, e topográficas e, possivelmente, como resultado de perturbações sofridas em passado recente (Battilani et al. 2005).

Considerando que duas áreas podem ser florísticamente semelhantes quando o índice de Jaccard é superior a 25\% (Mueller-Dombois \& Ellemberg 1974; Saiz, 1980), as seis áreas amostradas apresentaram-se muito semelhantes, com mais de $30 \%$ de similaridade no índice de Jaccard e acima de 45\% no índice de Sørenson (Tab. 3). Neste contexto, as pequenas diferenças na comparação florística, constatadas pelos índices de similaridade, também foram observadas na comparação 
Tabela 1. Relação das famílias e espécies coletadas nas florestas estacionais ribeirinhas das bacias hidrográficas dos rios Formoso, Perdido e Salobra, Serra da Bodoquena, MS, Brasil. Os especialistas que auxiliaram na determinação de todos ou parte dos taxas estão listados após cada família. Hábito: Árvore - Ar, Arbusto - Ab, Liana - L, Palmeira - P.

4 Chamissoa maximiliani Mart. ex Moq

5 Chamissoa sp.

3. ANACARDIACEAE

6 Astronium fraxinifolium Schott ex Spreng.

7 A. graveolens Jacq.

8 Lithraea molleoides (Vell.) Engl.

9 Myracrodruon urundeuva Allemão

10 Schinus terebinthifolius Raddi

11 Tapirira guianensis Aubl.

4. ANNONACEAE

12 Annona coriacea Mart.

13 Unonopsis lindmanii R.E. Fr.

14 Xylopia aromatica (Lam.) Mart.

5. APOCYNACEAE

15 Aspidosperma cuspa (Kunth) S.F. Blake ex Pittier peroba

16 A. cylindrocarpon Müll. Arg.

17 A. parvifolium A. DC.

18 A. polyneuron Müll. Arg.

19 A. subincanum Mart.

20 Forsteronia pubescens A. DC.

21 Prestonia coalita (Vell.) Woodson

22 Rhabdadenia pohlii Müll. Arg.

6. ARALIACEAE

23 Dendropanax affinis (Marchal) Gamerro \& Zuloaga

24 D. cuneatus (DC.) Decne. \& Planch.

25 Schefflera morototoni (Aubl.) Maguire, Steyerm. \& Frodin.

7. ARECACEAE

26 Acrocomia aculeata (Jacq.) Lodd. ex Mart.

27 Attalea phalerata Mart. ex Spreng.

28 Syagrus romanzoffiana (Cham.) Glassman

peroba guatambu

8. ARISTOLOCHIACEAE

29 Aristolochia esperanzae Kuntze

30 A. triangularis Cham.

31 Aristolochia sp. 1

32 Aristolochia sp. 2

9. ASTERACEAE

33 Mikania capricorni B.L. Rob.

34 Vernonia scabra Pers.

35 Eupatorium sp. 1

36 Eupatorium sp. 2

37 Eupatorium sp. 3

10. BIGNONIACEAE

38 Arrabidaea florida A. DC.

39 Callichlamys latifolia (Rich.) K. Schum.

40 Cuspidaria lateriflora (Mart.) A. DC.

41 Jacaranda cuspidifolia Mart.

42 Paragonia pyramidata (Rich.) Bureau

43 Tabebuia heptaphylla (Vell.) Toledo

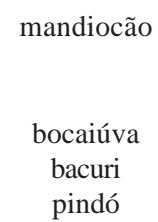

mandiocão

$$
\text { bacuri }
$$$$
\text { bocaiúva }
$$$$
\text { pindó }
$$

gonçalo
guarita
aroeira-branca
aroeira
aroeira-pimenteira
peito-de-pomba

$\mathrm{Ab}$

$\mathrm{Ab}$

$\mathrm{Ab}$

$\mathrm{L}$

L

Ar

$\mathrm{Ar}$

Ar

Ar

$\mathrm{Ar}$

Ar

marolo

pindaíba

pimenta-de-macaco
51662

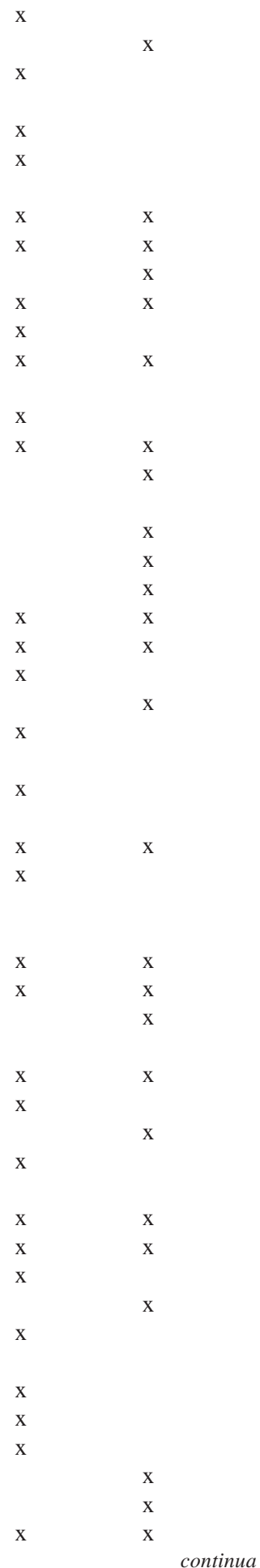


Tabela 1 (continuação)

Famílias/Espécies Nome regional Hábito $\begin{array}{ccc}\text { Registro Herbário } & \text { Floresta } & \text { Floresta } \\ \text { ESA/CGMS } & \text { Estacional } & \text { Estacional } \\ & \text { Semidecidual } & \text { Decidual } \\ & \text { Ribeirinha } & \text { Ribeirinha }\end{array}$

44 Tabebuia impetiginosa (Mart. ex DC.) Standl. piúva da mata 45 T. ochracea (Cham.) Standl.

46 T. roseo-alba (Ridl.) Sand.

11. BIXACEAE

47 Bixa orelana $\mathrm{L}$.

12. BORAGINACEAE

48 Cordia glabrata A. DC.

49 C. sellowiana Cham.

50 C. trichotoma (Vell.) Arráb. ex Steud.

51 Patagonula americana L.

52 Cordia sp.

13. BRASSICACEAE

53 Capparis prisca J.F. Macbr.

14. BURSERACEAE

54 Protium heptaphyllum (Aubl.) Marchand

15. CANNABACEAE

55 Celtis iguanaea (Jacq.) Sarg.

56 C. pubescens Spreng.

57 C. spinosa Spreng.

58 Trema micrantha (L.) Blume

59 Celtis sp.

16. CARICACEAE

60 Jacaratia spinosa (Aubl.) A. DC.

17. CELASTRACEAE

61 Hippocratea volubilis $\mathrm{L}$.

62 Maytenus ilicifolia (Schrad.) Planch.

63 M. macrodonta Reissek

64 Salacia elliptica (Mart. ex Schult.) G. Don

18. CLUSIACEAE

65 Garcinia gardneriana (Planch. \& Triana) Zappi bacupari

19. COMBRETACEAE

66 Combretum discolor Taub.

67 C. leprosum Mart.

68 Terminalia argentea Mart.

69 T. triflora (Griseb.) Lillo ipê-amarelo ipê-branco

louro-preto

chá-de-bugre

louro-pardo

guajuvira

70 Terminalia sp.

20. CONVOLVULACEAE

71 Ipomoea alba L.

72 Merremia umbellata (L.) Hallier f.

73 Ipomoea sp.

21. CUCURBITACEAE

74 Cayaponia podantha Cogn.

75 Momordica charantia L.

76 Psiguria sp.

22. DILLENIACEAE

77 Curatella americana L.

78 Dilleniaceae sp. 1

23. EUPHORBIACEAE

79 Adelia membranifolia (Müll. Arg.) Chodat \& Hassl.

80 Cnidoscolus cnicodendron Griseb.

81 Croton urucurana Baill.

82 Dalechampia scandens L.

83 Sapium hasslerianum Huber

84 Sebastiania brasiliensis Spreng.

85 S. discolor (Spreng.) Müll. Arg.

86 S. membranifolia Müll. Arg.

87 S. serrata (Baill. ex Müll. Arg.) Müll. Arg.

88 Acalypha sp. carne-de-vaca capitão alazão

viu-viu

(a)

$\mathrm{L}$
$\mathrm{L}$
$\mathrm{L}$

51691

51693

51694

51695

lixeira

cansanção

sangra-d'água

leiteiro

canela-de-cutia

sarandi

canela-de-cutia

L

L

Ar

L

51696

51697

$\mathrm{Ar}$

$\mathrm{Ab}$

Ar

$\mathrm{Ar}$

Ar

$\mathrm{Ar}$

$\mathrm{Ar}$

Ar

51688

51700

51703

51706

51709

51710

51711
$\mathrm{Ar}$

$\mathrm{Ar}$

Ar

Ar

Ar

Ar

Ar

$\mathrm{Ar}$

Ar

$\mathrm{Ab}$

$\mathrm{Ar}$

$\mathrm{Ab}$

Ar

L

Ar

Ar

Ar

Ar

51674

51679

51680

51682

51683

51684

$\begin{array}{ccc}51663 & \mathrm{X} & \\ 51664 / 17311 & \mathrm{X} & \mathrm{X} \\ 51665 & \mathrm{X} & \mathrm{X} \\ 51666 & \mathrm{X} & \mathrm{X} \\ 51667 / 17315 & \mathrm{X} & \\ 51668 / 17314 & \mathrm{X} & \mathrm{X} \\ 51670 / 17313 & \mathrm{X} & \mathrm{X} \\ 51671 / 17312 & \mathrm{X} & \mathrm{X} \\ 51669 & & \mathrm{X}\end{array}$

51677

$51678 / 17317$

$51685 / 17320$

(686/17319

$51699 / 17325$

$51702 / 17326$

$51708 / 17324$

$51698 / 17322$
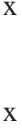

$\mathrm{x}$

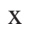

X

X

$\mathrm{X}$

$\mathrm{X}$

$\mathrm{x}$

X

X

X

$\mathrm{X}$

X

$\mathrm{X}$ 
Tabela 1 (continuação)

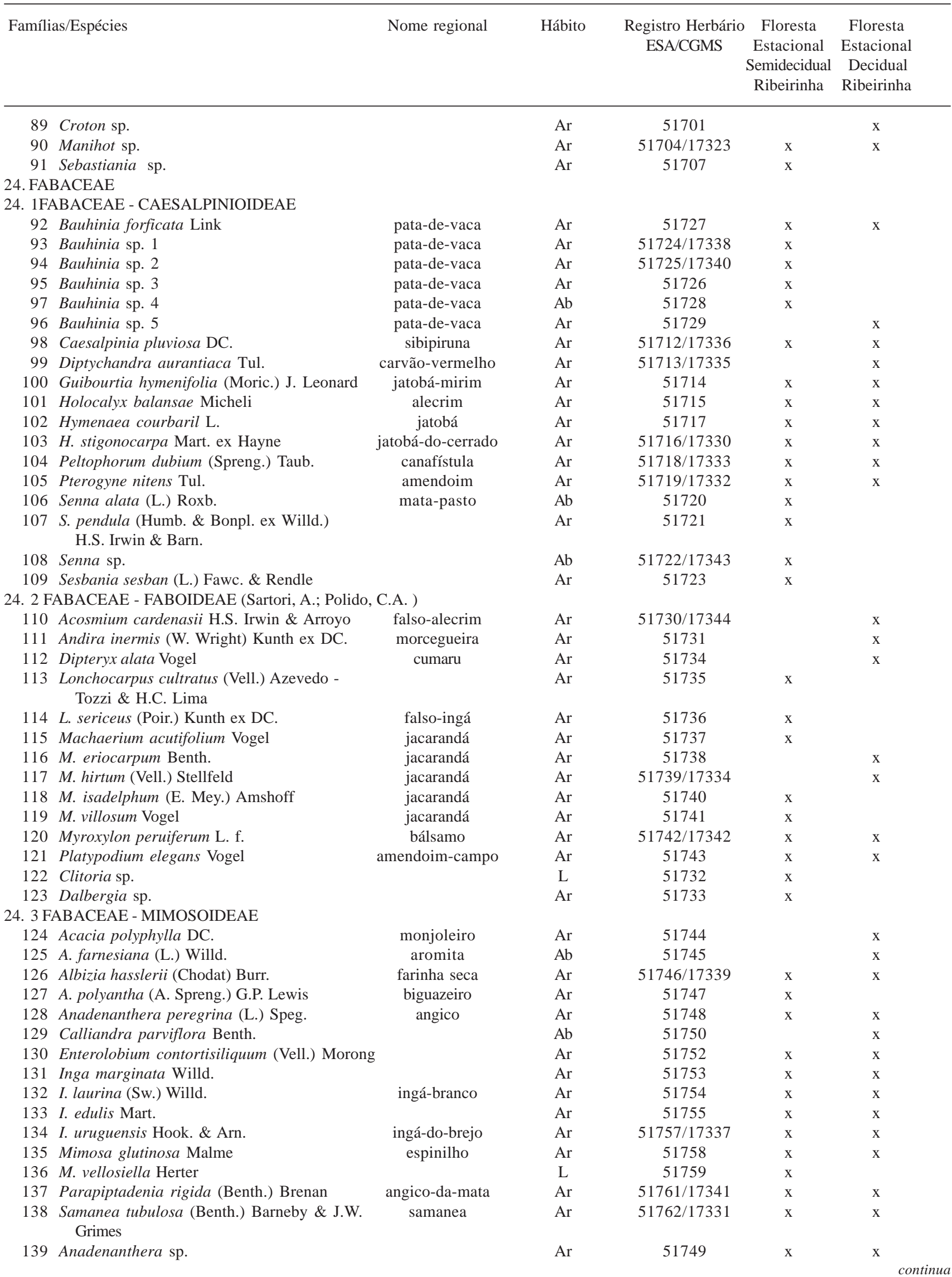


Tabela 1 (continuação)

\begin{tabular}{|c|c|c|c|c|c|}
\hline Famílias/Espécies & Nome regional & Hábito & $\begin{array}{c}\text { Registro Herbário } \\
\text { ESA/CGMS }\end{array}$ & $\begin{array}{l}\text { Floresta } \\
\text { Estacional } \\
\text { Semidecidual } \\
\text { Ribeirinha }\end{array}$ & $\begin{array}{c}\text { Floresta } \\
\text { Estacional } \\
\text { Decidual } \\
\text { Ribeirinha }\end{array}$ \\
\hline
\end{tabular}

$\begin{array}{ll}140 & \text { Calliandra sp. } \\ 141 & \text { Inga } \mathrm{sp} .1 \\ 142 & \text { Mimosa } \mathrm{sp} .\end{array}$

25. LAMIACEAE

143 Aegiphila sellowiana Cham.

144 A. candelabrum Briq.

145 Vitex cymosa Bertero ex Spreng.

26. LAURACEAE (Alves, F.M)

146 Licaria triandra (Sw.) Kosterm.

147 Nectandra hihua (Ruiz \& Pav.) Rohwer

148 N. megapotamica (Spreng.) Mez

27. LORANTHACEAE

149 Psittacanthus calyculatus (DC.) G. Don

150 Loranthaceae sp. 1

151 Loranthaceae sp. 2

28. MALPIGHIACEAE

152 Banisteriopsis pubipetala (A. Juss.) Cuatrec. cipó-de-pomba

153 Bunchosia paraguariensis Nied.

154 Heteropterys hypericifolia A. Juss.

155 Thryallis laburnum S. Moore

156 Banisteriospsis sp.

157 Heteropteris sp.

\section{MALVACEAE}

158 Apeiba tibourbou Aubl.

159 Bastardiopsis densiflora (Hook \& Arn ) Hace-de-macaco

160 Cestrum strigilatum Ruiz \& Pav.

161 Guazuma tomentosa Kunth chico-magro

162 G. ulmifolia Lam.

chico-magro

163 Helicteres lhotzkyana (Schott \& Endl.) K. Schum.

164 Sterculia apetala (Jacq.) H. Karst.

165 Luehea sp. 1

30. MELIACEAE

166 Cabralea canjerana (Vell.) Mart.

167 Cedrela fissilis Vell.

168 Guarea kuntiana A. Juss

169 Guarea guidonia (L.) Sleumer

170 Trichilia casaretti C. DC.

171 T. catigua A. Juss.

172 T. claussenii C. DC.

173 T. elegans A. Juss.

174 T. hirta L.

175 T. pallida Sw.

176 T. silvatica C. DC.

177 Trichilia $\mathrm{sp.}$

31. MORACEAE

178 Brosimum gaudichaudii Trécul

179 Ficus dendrocida Kunth

180 F. calyptroceras (Miq.) Miq.

181 F. enormis (Mart. ex Miq.) Mart.

182 F. gardneriana (Miq.) Miq.

183 F. gomelleira Kunth \& C.D. Bouché

184 F. guaranitica Chodat

185 F. insipida Willd.

186 F. pertusa L. f.

187 Maclura tinctoria (L.) D. Don ex Steud.

188 Sorocea sprucei (Baill.) J.F. Macbr.

189 Ficus sp. 1

190 Ficus sp. 2 mandovi

canjarana

cedro-branco

marinheiro

canjambo

catiguá-branco

pombeiro

catiguá-vermelho

catiguá-branco

mama-cadela

figueira-mata-pau

figueira

figueira-branca

amora-branca

figueira

$\begin{array}{ccc}\mathrm{Ab} & 51751 & \mathrm{x} \\ \mathrm{Ar} & 51756 / 17328 & \mathrm{x} \\ \mathrm{Ar} & 51760 & \mathrm{x} \\ & & \\ \mathrm{Ar} & 51763 & \mathrm{x} \\ \mathrm{Ab} & 51764 & \mathrm{x} \\ \mathrm{Ar} & 51765 / 17345 & \mathrm{x}\end{array}$

\section{$\mathrm{X}$ \\ $x$ \\ $\mathrm{X}$}

51766

$51767 / 17347$

51768

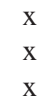

51769

51770

51771

51772

51774

51775

51777

51773

51776

51778

51779

51780

51781

$51782 / 17351$

$51783 / 17353$

51785

51784

51786

51787

$51788 / 17354$

$51789 / 17359$

$51790 / 17360$

51791

51792

51793

$51794 / 17361$

51795

51796/17355

$51797 / 17357$

51798

51799

51800/17367

51801

51802

$51803 / 17362$

$51804 / 17365$

51805

$51806 / 17366$

$51809 / 17363$

51810

51807

51808 
Tabela 1 (continuação)

\begin{tabular}{|c|c|c|c|c|c|}
\hline Famílias/Espécies & Nome regional & Hábito & $\begin{array}{c}\text { Registro Herbário } \\
\text { ESA/CGMS }\end{array}$ & $\begin{array}{c}\text { Floresta } \\
\text { Estacional } \\
\text { Semidecidual } \\
\text { Ribeirinha }\end{array}$ & $\begin{array}{c}\text { Floresta } \\
\text { Estacional } \\
\text { Decidual } \\
\text { Ribeirinha }\end{array}$ \\
\hline
\end{tabular}

\section{MYRSINACEAE}

191 Rapanea ferruginea (Ruiz \& Pav.) Mez

192 R. guianensis Aubl.

33. MYRTACEAE (Fiorela, F. M.)

193 Blepharocalyx salicifolius (Kunth) O. Berg

194 Calyptranthes sp. 1

195 Campomanesia eugenioides (Cambess.) D. Legrand

196 Eugenia dysenterica DC.

197 Eugenia egensis DC.

198 Eugenia florida DC.

199 Eugenia neoaustralis Sobral.

200 Eugenia paracatuana O. Berg

201 Eugenia pyriformis Cambess.

202 Eugenia repanda O. Berg

203 Hexachlamys edulis (O. Berg) Kausel \& D. Legrand

204 Myrcianthes pungens (O. Berg) D. Legrand

205 Psidium cattleianum Sabine

206 Campomanesia sp. 1

207 Campomanesia sp. 2

208 Campomanesia sp. 3

209 Eugenia sp. 1

210 Eugenia sp. 2

211 Eugenia sp. 3

212 Eugenia sp. 4

213 Myrcia sp.

34. NYCTAGINACEAE

214 Guapira areolata (Heimerl) Lundell

215 Guapira opposita (Vell.) Reitz

216 Pisonia aculeata L.

217 Pisonia zapallo Griseb.

218 Reichenbachia sp.

219 Neea hermaphrodita S. Moore

35. OLACACEAE

220 Ximenia americana L.

36. OLEACEAE

221 Chionanthus filiformis (Vell.) P.S. Green

222 Priogymnanthus hasslerianus (Chodat) P.S. Green

37. OPILIACEAE

223 Agonandra brasiliensis Miers ex Benth. \& Hook. f.

224 Agonandra sp.

38. PASSIFLORACEAE

225 Passiflora gibertii N.E. Br.

226 P. cincinnata Mast.

227 Passiflora sp.

39. PHYLLANTHACEAE

228 Phyllanthus sellowianus (Klotzsch) Müll. Arg.

229 Margaritaria nobilis L. f. 40.PIPERACEAE

230 Piper aduncum L.

231 P. amalago L.

232 P. angustifolium Lam.

233 P. arboreum Aubl.

$234 P$. chimonanthifolium Kunth

235 P. tuberculatum Jacq. capororoca

capororoca

Ar

cagaita

pessego-do-mato

\section{Ar}

$\mathrm{Ar}$

$\mathrm{Ar}$

$\mathrm{Ar}$

$\mathrm{Ab}$

$$
\begin{aligned}
& \mathrm{Ar} \\
& \mathrm{Ar}
\end{aligned}
$$

Ar

$\mathrm{Ar}$

$\mathrm{Ab}$

$\mathrm{Ar}$

Ar

Ar

$\mathrm{Ar}$

$\mathrm{Ar}$

$\mathrm{Ar}$

Ar

Ar

Ar

Ar

Ar

$\mathrm{Ar}$

$\mathrm{Ar}$

Ar

Ar

$\mathrm{Ar}$

$\mathrm{Ab}$

$\mathrm{Ab}$

$\mathrm{Ar}$

limãozinho

osso-de-burro

$\mathrm{Ar}$

$\mathrm{Ar}$

Ar

tingue-cuia

Ar

maracujazinho

Ar

L

L

L

$\mathrm{Ab}$

figueirinha

$\mathrm{Ar}$

falso-jaborandi

pimenta-de-macaco
$51841 / 17384$

$51842 / 17385$

51843

51844

\section{1}

51813

$51814 / 17368$

$51815 / 17369$

$51819 / 17380$

51820

51821

51822

51824

51825

51830

$$
\begin{gathered}
51832 / 17376 \\
51833
\end{gathered}
$$

$51816 / 17379$

$51817 / 17377$

$51818 / 17381$

$51826 / 17370$

$51827 / 17371$

$51828 / 17373$

$51829 / 17375$

$51831 / 17372$

51834

$51835 / 17383$

51836

$51838 / 17382$

51839

51840

$\mathrm{x}$

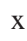

$\mathrm{x}$

$\mathrm{x}$

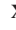

$\mathrm{x}$

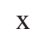

$\mathrm{x}$

$\mathrm{X}$

$\mathrm{x}$

$\mathrm{x}$

$\mathrm{X}$

$\mathrm{x}$

$51705 \quad x$

$51848 / 17386 \quad \mathrm{x}$

51849

51850

51851

51852

51853

51855 $\mathrm{x}$

$\mathrm{x}$

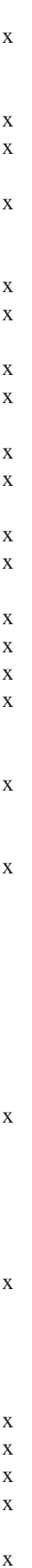


Tabela 1 (continuação)

\begin{tabular}{|c|c|c|c|c|c|}
\hline Famílias/Espécies & Nome regional & Hábito & $\begin{array}{l}\text { Registro Herbário } \\
\text { ESA/CGMS }\end{array}$ & $\begin{array}{l}\text { Floresta } \\
\text { Estacional } \\
\text { Semidecidual } \\
\text { Ribeirinha }\end{array}$ & $\begin{array}{c}\text { Floresta } \\
\text { Estacional } \\
\text { Decidual } \\
\text { Ribeirinha }\end{array}$ \\
\hline
\end{tabular}

\begin{tabular}{|c|c|c|c|c|c|}
\hline 236 Piper sp. & & $\mathrm{Ab}$ & 51854 & $\mathrm{x}$ & \\
\hline \multicolumn{6}{|l|}{ 41. POACEAE } \\
\hline 237 Guadua angustifolia Kunth & taquaruçu & $\mathrm{Ar}$ & $51856 / 17388$ & & $\mathrm{x}$ \\
\hline $\begin{array}{l}238 \text { G. cf. chacoensis (Rojas) Londõno \& } \\
\text { P.M. Peterson }\end{array}$ & taquaruçu & $\mathrm{Ar}$ & $51857 / 17387$ & $\mathrm{x}$ & $\mathrm{x}$ \\
\hline \multicolumn{6}{|l|}{ 42. PHYTOLACCACEAE } \\
\hline 239 Gallesia integrifolia (Spreng.) Harms & pau-d'alho & $\mathrm{Ar}$ & 51858 & & $\mathrm{x}$ \\
\hline 240 Rivinia humilis L. & & $\mathrm{Ab}$ & 51859 & & $\mathrm{x}$ \\
\hline 241 Seguieria floribunda Benth. & & $\mathrm{L}$ & 51860 & $\mathrm{x}$ & \\
\hline \multicolumn{6}{|l|}{ 43. POLYGONACEAE } \\
\hline 242 Triplaris americana $\mathrm{L}$. & novateiro & $\mathrm{Ar}$ & $51861 / 17389$ & $\mathrm{x}$ & \\
\hline 243 Coccoloba cujabensis Wedd. & canjiquinha & $\mathrm{Ab}$ & 51862 & & $\mathrm{x}$ \\
\hline \multicolumn{6}{|l|}{ 44. RHAMNACEAE } \\
\hline 244 Colubrina glandulosa Perkins & & $\mathrm{Ar}$ & 51863 & $\mathrm{x}$ & $\mathrm{x}$ \\
\hline 245 Gouania mollis Reissek & & $\mathrm{Ar}$ & 51864 & & $\mathrm{x}$ \\
\hline 246 G. lupuloides (L.) Urb. & & $\mathrm{L}$ & 51865 & & $\mathrm{x}$ \\
\hline 247 Rhamnidium elaeocarpum Reissek & cabriteiro & $\mathrm{Ar}$ & $51866 / 17390$ & $\mathrm{x}$ & $\mathrm{x}$ \\
\hline \multicolumn{6}{|l|}{ 45. RUBIACEAE } \\
\hline 248 Alibertia sessilis (Vell.) K. Schum. & marmelo & $\mathrm{Ar}$ & 51867 & $\mathrm{x}$ & $\mathrm{x}$ \\
\hline 249 A. edulis (Rich.) A. Rich. ex DC. & marmelo & $\mathrm{Ar}$ & 51868 & $\mathrm{x}$ & $\mathrm{x}$ \\
\hline 250 Calycophyllum multiflorum Griseb. & castelo & $\mathrm{Ar}$ & $51870 / 17396$ & $\mathrm{x}$ & $\mathrm{x}$ \\
\hline 251 Genipa americana L. & jenipapo & $\mathrm{Ar}$ & $51872 / 17394$ & $\mathrm{x}$ & $\mathrm{x}$ \\
\hline 252 Guettarda viburnoides Cham. \& Schltdl. & veludo & $\mathrm{Ar}$ & $51873 / 17393$ & $\mathrm{x}$ & $\mathrm{x}$ \\
\hline 253 Psychotria carthagenensis Jacq. & & $\mathrm{Ab}$ & $51874 / 17392$ & $\mathrm{x}$ & $\mathrm{x}$ \\
\hline 254 Randia $\operatorname{armata}(\mathrm{Sw}.) \mathrm{DC}$. & veludo-de-espinho & $\mathrm{Ab}$ & 51876 & $\mathrm{x}$ & $\mathrm{x}$ \\
\hline 255 Alibertia sp. & marmelo & $\mathrm{Ar}$ & $51869 / 17397$ & $\mathrm{x}$ & \\
\hline 256 Calycophyllum sp. & & $\mathrm{Ar}$ & 51871 & & $\mathrm{x}$ \\
\hline 257 Psychotria sp. & & $\mathrm{Ab}$ & $51875 / 17395$ & & $\mathrm{x}$ \\
\hline \multicolumn{6}{|l|}{ 46. RUTACEAE } \\
\hline 258 Balfourodendron riedelianum (Engl.) Engl. & pau-marfim & $\mathrm{Ar}$ & $51877 / 17402$ & & $\mathrm{x}$ \\
\hline 259 Esenbeckia leiocarpa Engl. & guarantã & $\mathrm{Ar}$ & 51879 & & $\mathrm{x}$ \\
\hline 260 Pilocarpus pennatifolius Lem. & & $\mathrm{Ab}$ & 51880 & & $\mathrm{x}$ \\
\hline 261 Helietta apiculata Benth. & cun-cun & $\mathrm{Ar}$ & $51881 / 17411$ & $\mathrm{x}$ & \\
\hline 262 Zanthoxylum hasslerianum (Chodat) Pirani & mamica-de-porca & $\mathrm{Ar}$ & $51882 / 17399$ & $\mathrm{x}$ & $\mathrm{x}$ \\
\hline 263 Z. rhoifolium Lam. & mamica-de-porca & $\mathrm{Ar}$ & 51883 & $\mathrm{x}$ & $\mathrm{x}$ \\
\hline 264 Citrus sp. & & $\mathrm{Ar}$ & $51878 / 17400$ & $\mathrm{x}$ & \\
\hline 265 Zanthoxylum sp. 1 & & $\mathrm{Ar}$ & $51884 / 17401$ & $\mathrm{x}$ & \\
\hline 266 Zanthoxylum sp. 2 & & $\mathrm{Ar}$ & 51885 & $\mathrm{x}$ & \\
\hline 267 Zanthoxylum sp. 3 & & $\mathrm{Ar}$ & 51886 & $\mathrm{x}$ & $\mathrm{x}$ \\
\hline \multicolumn{6}{|l|}{ 47. SALICACEAE } \\
\hline 268 Casearia gossypiosperma Briq. & espeteiro & $\mathrm{Ar}$ & $51887 / 17409$ & $\mathrm{x}$ & $\mathrm{x}$ \\
\hline 269 C. rupestris Eichler & pururuca & $\mathrm{Ar}$ & $51888 / 17403$ & $\mathrm{x}$ & \\
\hline 270 Casearia sylvestris Sw. & guaçatonga & $\mathrm{Ar}$ & $51890 / 17406$ & $\mathrm{x}$ & $\mathrm{x}$ \\
\hline 271 Prockia crucis P. Browne ex L. & & $\mathrm{Ab}$ & 51891 & $\mathrm{x}$ & $\mathrm{x}$ \\
\hline 272 Xylosma venosum N.E. Brown & & $\mathrm{Ar}$ & 51892 & & $\mathrm{x}$ \\
\hline 273 Casearia sp. & & $\mathrm{Ar}$ & $51889 / 17404$ & $\mathrm{x}$ & \\
\hline \multicolumn{6}{|l|}{ 48. SAPINDACEAE } \\
\hline 274 Allophyllus edulis (St. Hil.) Radlk. & & $\mathrm{Ar}$ & $51893 / 17413$ & $\mathrm{x}$ & \\
\hline 275 Averrhoidium paraguayense Radlk. & maria-preta & $\mathrm{Ar}$ & $51894 / 17412$ & $\mathrm{x}$ & $\mathrm{x}$ \\
\hline 276 Cardiospermum grandiflorum Sw. & poca & $\mathrm{L}$ & 51895 & & \\
\hline 277 Cupania castaneaefolia Mart. & camboatã & $\mathrm{Ar}$ & $51896 / 17410$ & $\mathrm{x}$ & $\mathrm{x}$ \\
\hline 278 Diatenopteryx sorbifolia Radlk. & & $\mathrm{Ar}$ & 51897 & $\mathrm{x}$ & \\
\hline 279 Dilodendron bipinnatum Radlk. & maria-mole & $\mathrm{Ar}$ & $51898 / 17414$ & $\mathrm{x}$ & $\mathrm{x}$ \\
\hline 280 Magonia pubescens A. St.-Hil. & timbó & $\mathrm{Ar}$ & 51899 & $\mathrm{x}$ & \\
\hline 281 Paullinia pinnata $\mathrm{L}$. & cipó-cinco-folhas & $\mathrm{L}$ & 51900 & $\mathrm{x}$ & $\mathrm{x}$ \\
\hline 282 Sapindus saponaria L. & saboneteira & $\mathrm{Ar}$ & 51901 & $\mathrm{x}$ & \\
\hline 283 Serjania caracasana (Jacq.) Willd. & & $\mathrm{L}$ & $51902 / 17415$ & $\mathrm{x}$ & $\mathrm{x}$ \\
\hline 284 S. erecta Radlk. & & $\mathrm{L}$ & $51903 / 17417$ & $\mathrm{x}$ & $\mathrm{x}$ \\
\hline
\end{tabular}


Tabela 1 (continuação)

\begin{tabular}{|c|c|c|c|c|c|}
\hline Famílias/Espécies & Nome regional & Hábito & $\begin{array}{l}\text { Registro Herbário } \\
\text { ESA/CGMS }\end{array}$ & $\begin{array}{c}\text { Floresta } \\
\text { Estacional } \\
\text { Semidecidual } \\
\text { Ribeirinha }\end{array}$ & $\begin{array}{c}\text { Floresta } \\
\text { Estacional } \\
\text { Decidual } \\
\text { Ribeirinha }\end{array}$ \\
\hline 285 Urvillea laevis Radlk. & & $\mathrm{L}$ & $51905 / 17416$ & $\mathrm{x}$ & \\
\hline 286 Talisia esculenta (A. St.-Hil.) Radlk. & pitomba & $\mathrm{Ar}$ & 51906 & $\mathrm{x}$ & $\mathrm{x}$ \\
\hline 287 Urvillea sp. & & $\mathrm{L}$ & 51904 & $\mathrm{x}$ & \\
\hline \multicolumn{6}{|l|}{ 49. SAPOTACEAE } \\
\hline $\begin{array}{c}288 \text { Chrysophyllum gonocarpum (Mart. \& } \\
\text { Eichler ex Miq.) Engl. }\end{array}$ & aguaí & $\mathrm{Ar}$ & 51907 & $\mathrm{x}$ & $\mathrm{x}$ \\
\hline 288 C. marginatum (Hook. \& Arn.) Radlk. & leiteiro & $\mathrm{Ar}$ & $51908 / 17418$ & & $\mathrm{x}$ \\
\hline 290 Pouteria glomerata (Miq.) Radlk. & laranjinha & $\mathrm{Ab}$ & 51909 & $\mathrm{x}$ & \\
\hline \multicolumn{6}{|l|}{ 50. SIMAROUBACEAE } \\
\hline 291 Castela tweedii Planch. & & $\mathrm{Ab}$ & $51910 / 17419$ & $\mathrm{x}$ & $\mathrm{x}$ \\
\hline \multicolumn{6}{|l|}{ 51. SMILACACEAE } \\
\hline 292 Smilax fluminensis Steud. & japecanga & $\mathrm{L}$ & 51911 & $\mathrm{x}$ & $\mathrm{x}$ \\
\hline \multicolumn{6}{|l|}{ 52. SOLANACEAE } \\
\hline 293 Cestrum strigillatum Ruiz et Pav. & & $\mathrm{Ab}$ & 51912 & $\mathrm{x}$ & $\mathrm{x}$ \\
\hline 294 Solanum amygdalifolium Steud. & & $\mathrm{L}$ & 51914 & & $\mathrm{x}$ \\
\hline 295 Markea sp. & & $\mathrm{Ab}$ & 51913 & & $\mathrm{x}$ \\
\hline 296 Solanum sp. & & $\mathrm{Ar}$ & 51915 & $\mathrm{x}$ & $\mathrm{x}$ \\
\hline \multicolumn{6}{|l|}{ 53. THEOPHRASTACEAE } \\
\hline 297 Clavija nutans (Vell.) B. Ståhl & chá-de-bugre & $\mathrm{Ab}$ & 51916 & $\mathrm{x}$ & $\mathrm{x}$ \\
\hline \multicolumn{6}{|l|}{ 54. URTICACEAE } \\
\hline 298 Boehmeria caudata Sw. & & $\mathrm{Ar}$ & $51917 / 17420$ & $\mathrm{x}$ & \\
\hline 299 Cecropia pachystachya Trécul & embaúba & $\mathrm{Ar}$ & 51918 & $\mathrm{x}$ & $\mathrm{x}$ \\
\hline 300 Urera baccifera (L.) Gaudich. ex Wedd. & urera & $\mathrm{Ar}$ & $51919 / 17421$ & & $\mathrm{x}$ \\
\hline 301 Urerasp. & & $\mathrm{Ab}$ & 51920 & $\mathrm{x}$ & \\
\hline \multicolumn{6}{|l|}{ 55.VITACEAE } \\
\hline 302 Cissus erosa Rich. & cipó-de-arraia-liso & $\mathrm{L}$ & 51921 & $\mathrm{x}$ & $\mathrm{x}$ \\
\hline \multicolumn{6}{|l|}{ 56.VERBENACEAE } \\
\hline 303 Aloysia virgata (Ruiz \& Pav.) Juss. & lixa & $\mathrm{Ar}$ & 51922 & $\mathrm{x}$ & $\mathrm{x}$ \\
\hline 304 Cytharexylum myrianthum Cham. & pau-viola & $\mathrm{Ar}$ & 51923 & $\mathrm{x}$ & \\
\hline 305 Lantana canescens Kunth & lantana & $\mathrm{Ab}$ & 51924 & $\mathrm{x}$ & \\
\hline 306 L. trifolia L. & uvinha-do-campo & $\mathrm{Ab}$ & 51925 & $\mathrm{x}$ & \\
\hline 307 Lippia alba (Mill.) N.E. Br. & cidreira-do-campo & $\mathrm{Ar}$ & 51926 & $\mathrm{x}$ & $\mathrm{x}$ \\
\hline
\end{tabular}

estrutural, revelada pela análise de correspondência (Fig. 4). As pequenas diferenças observadas entre as áreas 4 Campo Verde e 5 - Santa Laura, podem ser devido às preferências das espécies ao habitat, por aleatoriedade na reocupação de áreas com histórico de degradação intenso ou aspectos biogeográficos comprovados no parágrafo subseqüente.

Verificou-se nos trechos de florestas estacionais ribeirinhas estudadas uma composição florística mista, onde várias espécies encontradas são citadas por Prado \& Gibbs (1993), como sendo parte das formações pleistocênicas residuais, associadas a paleoclimas secos, que ocorrem em três núcleos na América do Sul. Algumas espécies encontradas no presente estudo ocorrem nessas formações pleistocênicas mais restritas a áreas secas, como Celtis pubescens Spreng. (Cannabaceae), enquanto outras são comuns nas partes mais úmidas dessas formações como Hymenaea courbaril L. (Fabaceae), espécie de distribuição Amazônica. Outras espécies são encontradas em áreas de várzea sazonalmente inundáveis nos rios da Amazônia e nas áreas de mata de galeria em savanas inundáveis da bacia amazônica na Bolívia, como Casearia gossypiosperma Briq. (Salicaceae) e Vitex cymosa Bertero ex Spreng. (Lamiaceae) (Klinge et al. 1990). Espécies, como Tabebuia heptaphylla (Vell.) Toledo (Bignoniaceae), são freqüentes no eixo ArgentinaParaguai, nas áreas úmidas do Chaco, atingindo o Sul do Brasil indo até o Nordeste via Mata Atlântica (Gentry 1992). Sterculia apetala (Jacq.) H. Karst. (Malvaceae) e Guibourtia hymenifolia (Moric.) J. Leonard (Fabaceae) são espécies típicas da caatinga arbórea (Pott \& Pott 2003). Enterolobium contortisiliquum (Vell.) Morong (Fabaceae), típicas das áreas de matas semidecíduas. Unonopsis lindmanii R.E. Fr. (Annonaceae), é uma espécie ombrófila de distribuição geográfica restrita ao Brasil Central (Oliveira Filho \& Ratter 2002). Nos terrenos planos contém certas árvores da Mata Atlântica, de distribuição mais ampla, como Parapiptadenia rigida 
Fazenda Baía Bonita

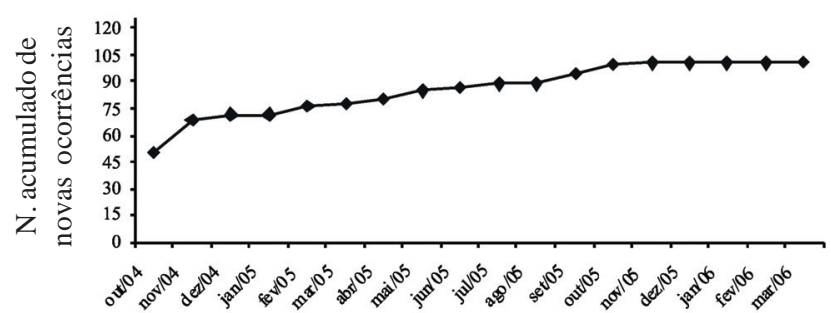

Fazenda Harmonia

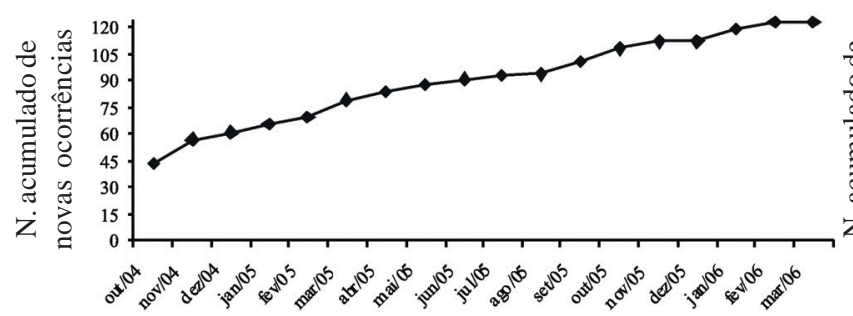

Fazenda Santa Laura

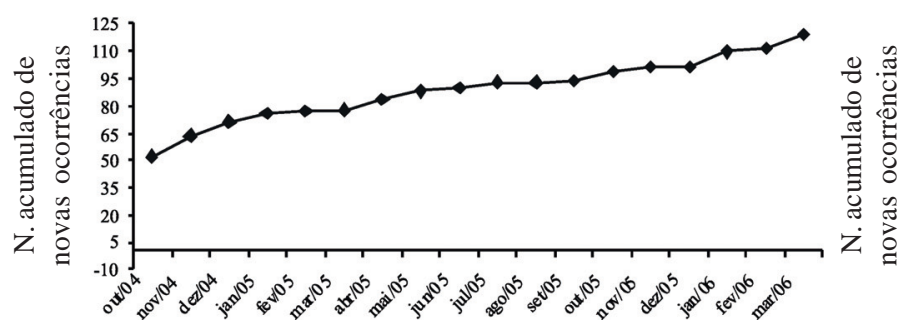

Meses de coleta
Fazenda América
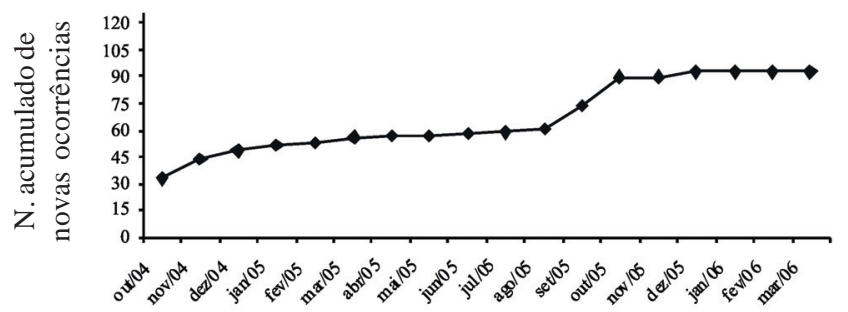

Fazenda Campo Verde

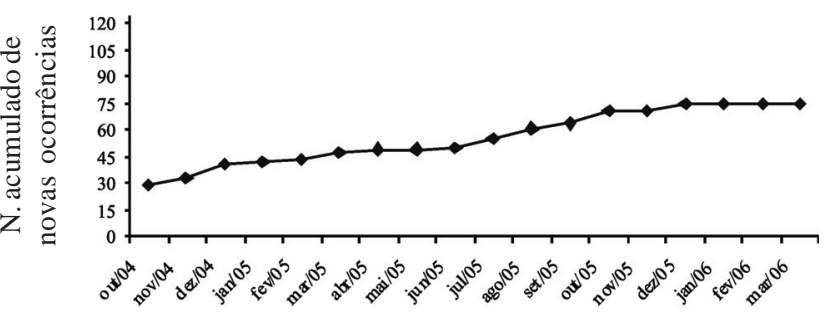

Fazenda Rancho Branco

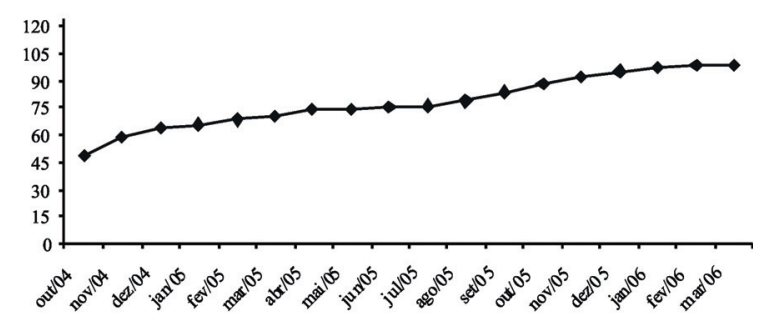

Meses de coleta

Figura 2. Número acumulado de novas ocorrências, de acordo com os meses, nos pontos amostrados das florestas estacionais ribeirinhas da bacia hidrográfica do rio Formoso e Parque Nacional da Serra da Bodoquena, MS, Brasil.

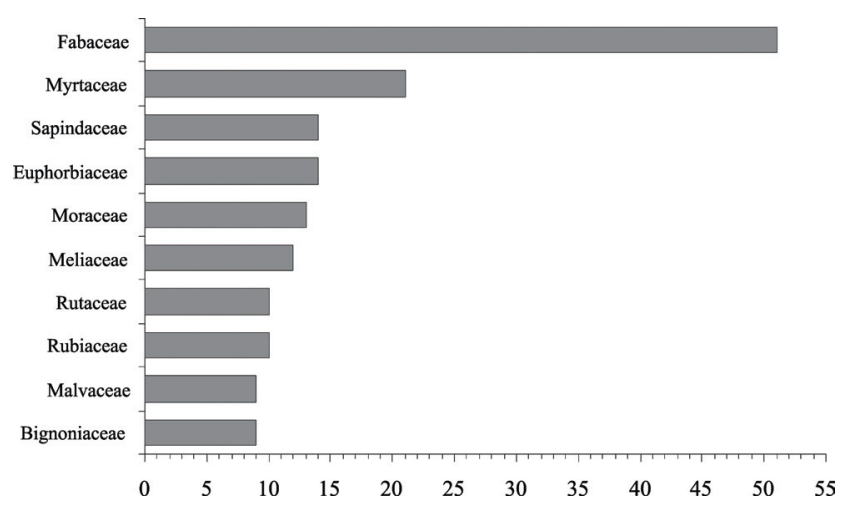

Figura 3. Famílias de maior riqueza em florestas nativas ribeirinhas da Bacia Hidrográfica do rio Formoso e Parque Nacional da Serra da Bodoquena, MS, Brasil.
Tabela 2. Total de espécies agrupadas por hábito e as famílias de maior riqueza nessas formas de vida.

\begin{tabular}{lcc}
\hline Hábito & Total de espécies & Famílias de maior riqueza \\
\hline Árvores & 208 & Fabaceae $(21 \%)$ \\
& & Myrtaceae $(9 \%)$ \\
Arbustos & 51 & Meliaceae $(6 \%)$ \\
& & Piperaceae $(14 \%)$ \\
& & Fabaceae $(12 \%)$ \\
Lianas & 45 & Rubiaceae $(6 \%)$ \\
& & Sapindaceae $(13 \%)$ \\
& & Aristolochiaceae $(9 \%)$ \\
& & Bignoniaceae $(7 \%)$ \\
Palmeiras & 03 & Convolvulaceae $(7 \%)$ \\
& & Cucurbitaceae $(7 \%)$ \\
& & Arecaceae $(100 \%)$ \\
\hline
\end{tabular}


Tabela 3. Índices de similaridade entre os trechos florestais amostrados na Serra da Bodoquena, MS, Brasil

\begin{tabular}{|c|c|c|c|c|c|c|c|c|c|c|}
\hline & \multicolumn{5}{|c|}{ Jaccard $(\%)$} & \multicolumn{5}{|c|}{ Sørenson $(\%)$} \\
\hline & Área 2 & Área 3 & Área 4 & Área 5 & Área 6 & Área 2 & Área 3 & Área 4 & Área 5 & Área 6 \\
\hline Área 1 - Faz. América & 61,90 & 53,14 & 43,10 & 53,64 & 47,14 & 76,47 & 69,40 & 60,24 & 69,83 & 64,08 \\
\hline Área 2 - Faz. Baía Bonita & & 65,05 & 38,46 & 51,21 & 58,99 & & 78,82 & 55,56 & 67,73 & 74,20 \\
\hline Área 3 - Faz. Harmonia & & & 31,75 & 49,63 & 57,65 & & & 48,19 & 66,33 & 73,14 \\
\hline Área 4 - Faz. Campo Verde & & & & 47,98 & 30,95 & & & & 64,85 & 47,27 \\
\hline Área 5 - Faz. Santa Laura & & & & & 39,27 & & & & & 56,40 \\
\hline
\end{tabular}

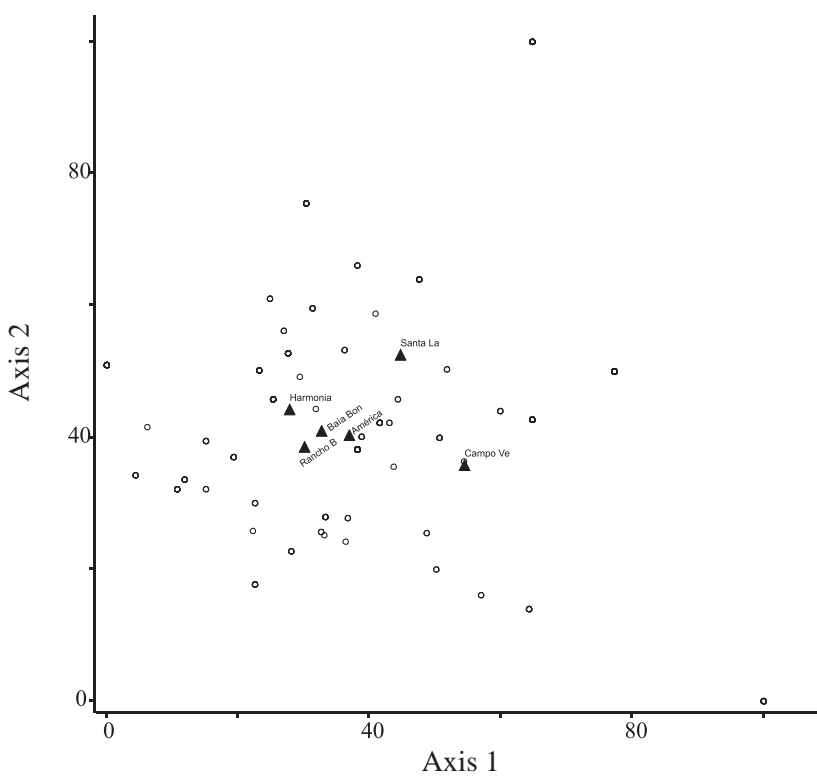

Figura 4. Ordenação das espécies e áreas de amostragem pela Análise de Correspondência, utilizando uma matriz de presença×ausência de espécies nas florestas estacionais ribeirinhas da Serra da Bodoquena, MS, Brasil.

(Benth.) Brenan (Fabaceae), Patagonula americana L. (Boraginaceae) e Myrcianthes pungens (O. Berg) D. Legrand (Myrtaceae) (Pott \& Pott 2003). Existem também espécies das matas de "palo-branco", que fazem parte das matas de transição do Chaco, na Argentina, como Calycophyllum multiflorum Griseb. (Rubiaceae) (Pott \& Pott 2003).

Os resultados obtidos neste trabalho contribuem para o conhecimento da flora sul-mato-grossense, e sua distribuição geográfica, reforçando a necessidade de conservação destas matas ribeirinhas, além de fornecer subsídios para os planos de restauração das áreas degradadas do entorno da unidade de conservação e das áreas de proteção permanente dos rios ocorrentes na região. Entretanto, existe a necessidade de estudos complementares em outros trechos de florestas estacionais ribeirinhas, com as mesmas características físicas das áreas estudadas, de forma a possibilitar comparações quanto à riqueza florística.

\section{Agradecimentos}

Os autores agradecem ao IBAMA - regional de Bonito, MS, em especial ao Dr. Adílio Valadão de Miranda (Chefe do Parque Nacional da Serra da Bodoquena), Ivan Salzo e Alexandre Matos Pereira, pelo apoio logístico, auxílio na caracterização das áreas amostradas e levantamento de campo; ao Sr. Nelson Izidoro Chemin Junior e Luiz de Brito por autorizar a realização deste estudo em suas propriedades; a Profa. Dra. Ângela Lúcia B. Sartori, ao Marcos Sobral, Carol Polido, Flávio Alves e Fiorella F.M. Capelo, pela ajuda na identificação do material botânico.

\section{Referências bibliográficas}

Alvarenga, S.M.; Brasil, A.E. \& Del'arco, D.M. 1982. Projeto RADAMBRASIL, Folha SF-21 - Campo Grande, 2- Geomorfologia. Rio de Janeiro. v. 28, 125-18 p.

APG II. 2003. An update of the Angiosperm Phylogeny Group classification for the orders and families of flowering plants: APG II. Botanical Journal of the Linnean Society 141: 399-436.

Battilani, J.L.; Scremin-Dias E. \& Souza, A.L.T. 2005. Fitossociologia de um trecho da mata ciliar do rio da Prata, Jardim, MS, Brasil. Acta Botanica Brasilica 19: 597-608.

Bertoni, J.E.A. \& Martins, F.R. 1987. Composição florística de uma floresta ripária na Reserva Estadual de Porto Ferreira, SP. Acta Botanica Brasílica 1: 17-16.

Cavassan, O.; Cesar, O. \& Martins, F.R. 1984. Fitossociologia da vegetação arbórea da Reserva Estadual de Bauru, estado de São Paulo. Revista Brasileira de Botânica 7: 91-106.

Cole, M.M. 1986. The savannas. Biogeography and geobotany. London, Academic Press.

Damasceno Junior G.A.; Nakajima J.N. \& Rezende U.M. 2000. A floristic survey of the Rio Negro, Rio Aquidauana, and Rio Miranda watersheds (headwaters) of the Pantanal, Mato Grosso do Sul, Brasil. Pp. 34-43. In: P.W. Willink; B. Chernoff; L.E. Alonso; J.R. Montambaut \& R. Lourival (eds.). A biological assessment of the Aquatic Ecosystems of the Pantanal, Mato Grosso do Sul, Brasil. RAP. Bulletin of Biological Assessment 18. Conservation International, Washington, DC.

Dislich, R. \& Mantovani, W. 1998. A flora de epífitas vasculares da reserva da Cidade Universitária "Armando Salles de Oliveira" (São Paulo, Brasil). Boletim de Botânica da Universidade de São Paulo 17: 61-83

Embrapa, 1999. Sistema brasileiro de classificação de solos. Rio de Janeiro, Empresa Brasileira de Pesquisa Agropecuária, Centro Nacional de Pesquisas de Solos. 
Felfili, J.M. 2003. Fragmentos florestais estacionais do Brasil central: diagnóstico e proposta de corredores ecológicos. Pp. 139-160. In: Costa, R. B. Fragmentação florestal e alternativas de desenvolvimento rural na região Centro-Oeste. Campo Grande, UCDB.

Felfili, J.M. \& Silva Junior, M.C. (orgs.). 2001a. Biogeografia do bioma cerrado. Estudo fitofisionomico na Chapada do Espigão Mestre do São Francisco. Brasília, UnB.

Felfili, J.M.; Mendonça, R.C.; Walter, B.M.T.; Silva Junior, M.C.; Nóbrega, M.G.G.; Fagg, C.W.; Sevilha, A.C. \& Silva, M.A. 2001b. Flora Fanerogâmica das Matas de Galeria e Ciliares do Brasil Central. Pp. 195-263. In: J.F. Ribeiro; C.E.L. Fonseca \& J.C. Souza-Silva. Cerrado: caracterização e recuperação de Matas de Galeria. Planaltina, EMBRAPA/Cerrados.

Gentry, A. 1992. Tropical forest biodiversity:distribution patterns. Oikos 63: 19-28.

Jaccard, P. 1912. The distribution of the flora the alpine zone. New Phytologist 11: 37-50.

Klinge, H.; Junk, W.J. \& Revilla, C.J. 1990. Status and distribution of forested wetlands in tropical South America. Forest Ecology and Management 33/34: 81-101.

Koppen, W.P. 1948. Climatologia. México, Fondo de Cultura Econômica.

Kotchetkoff, H.O. 2003. Caracterização da Vegetação Natural de Ribeirão Preto, SP: Bases para Conservação. Ribeirão Preto. Tese de Doutorado, São Paulo, Universidade de São Paulo.

Leitão Filho, H.F. 1982. Aspectos taxonômicos das florestas do estado de São Paulo. Silvicultura em São Paulo 16: 197-206.

Marimon, B.S.; Felfili J.M. \& Haridasan, M. 2001. Studies in monodominant forests in eastern Mato Grosso, Brasil: I. A forest of Brosimum rubescens Taub. Edinburgh Journal of Botany 58: $123-137$.

Mendonça, R.C.; Felfili, J.M.; Silva Jr., M.C.; Rezende, A.V.; Nogueira, P.E.; Walter, B.M.T. \& Filgueiras, T.S. 1998. Flora vascular do cerrado. Pp. 289-539. In: S.M. Sano \& S.P. Almeida (eds.). Cerrado: Ambiente e Flora. Planaltina, Embrapa - CPAC.

Missouri Botanical Garden, 2007. Missouri Botanical Garden W3 Tropicos. Vascular Trópicos Nomenclatural Database no ar desde 1995. Disponível em <http://www.mobot.org/W3T/Search/ vast.html>. (Acesso em: 25/02/2007).

Mueller-Dombois, D. \& Ellemberg, H. 1974. Aims and methods vegetation ecology. New York, Wiley.

Nunes, Y.R.F.; Mendonça, A.V.R.; Botezelli, L.; Machado, E.L.M. \& Oliveira Filho, A.T. 2003. Variações da fisionomia, diversidade e composição de guildas da comunidade arbórea em um fragmento de floresta semidecidual em Lavras, MG. Acta Botanica Brasílica 17: 213-231

Oliveira Filho, A.T. \& Ratter, J.A. 1995. Study of Origin of Central Brazilian Forest by the analysis of Plant Species Distribuition Patterns. Edinburgh Journal of Botany 52: 141-194.

Oliveira Filho, A.T. \& Ratter, J.A. 2002. Vegetation physiognomies and woody flora of the Cerrado Biome. Pp. 91-120. In: The Cerrados of Brazil: ecology and natural history of a Neotropical savanna. New York, Columbia University Press.

Pagano, S.N. \& Leitão Filho, H.F. 1987. Composição florística do estado arbóreo da mata mesófila semidecidua, no município de Rio Claro (estado de São Paulo). Revista Brasileira de Botânica 10: 37-47.
Pagotto, T.C.S. \& Souza, P.R. 2006. Biodiversidade do Complexo Aporé-Sucuriú. Campo Grande, UFMS.

Pott, A. \& Pott, V.J. 2003. Espécies de Fragmentos Florestais em Mato Grosso do Sul. In: COSTA, R.B. Fragmentação Florestal e Alternativas de Desenvolvimento Rural na Região Centro-Oeste. Campo Grande, UCDB.

Prado, D.E. \& Gibbs, P.E. 1993. Petterns of species distribution in the dry seasonal forests of South America. Annals of Missouri Botanical Garden 80: 902-927.

Ribeiro, J.F. \& Walter, B.M.T. 1998. Fitofisionomia do bioma Cerrado. Pp. 89-152. In: M.S. Sano \& S.P. Almeida. Cerrado: ambiente e flora. Planaltina, Embrapa.

Rodrigues, R.R. 2004. Uma discussão nomenclatural das formações ciliares. Pp. 91-99. In: R.R. Rodrigues \& H.F. Leitão Filho Matas ciliares: conservação e recuperação. São Paulo, EDUSP.

Rodrigues, R.R. \& Nave, A.G. 2004. Heterogeneidade Florística das Matas Ciliares. Pp. 45-71. In: R.R. Rodrigues \& H.F. Leitão Filho (orgs.). Matas Ciliares: conservação e recuperação. São Paulo, EDUSP.

Rodrigues, R.R.; Morellato, L.P.C.; Joly, C.A. \& Leitão Filho, H.F. 1989. Estudo florístico em um gradiente altitudinal de mata estacional mesófila semidecidua, na Serra do Japi, Jundiaí, SP. Revista Brasileira de Botânica 12: 71-84.

Romagnolo, M.B. \& Souza, M.C. 2000. Analise floristica e estrutural de florestas ripárias do alto Rio Paraná, Taquaruçu, MS. Acta Botanica Brasilica 14: 163-174.

Saiz, F. 1980. Experiencias en el uso de criterios de similaritud en el estudio de comunidades. Experimental Biology and Medicine 13: 387-402.

Salis, S.M.; Tamashiro, J.Y. \& Joly, C.A. 1994. Floristica e fitossociologia do estrato arbóreo de um remanescente de mata ciliar do rio Jacaré-Pepira, Brotas, SP. Revista Brasileira de Botânica 17: 93-103.

Sallun Filho, W.; Karmann, I. \& Boggiani, P.C. 2004. Paisagen Cársticas da Serra da Bodoquena, MS. In: V. Mantesso Neto; A. Bartorelli; C. Dal Ré Carneiro \& B.B. Brito-Neves (orgs.) Geologia do Continente Sul-Americano 1: 423-433.

Santin, D.A. 1999. Fragmentos Florestais do município de Campinas (SP): Mapeamento, Caracterização Fisionômica e Florística visando a Conservação. Tese de Doutorado, Campinas, Universidade Estadual de Campinas.

Sciamarelli, A. 2005. Estudo florístico e fitossociológico da “Mata de Dourados" Fazenda Paradouro, Dourados, Mato Grosso do sul, Brasil. Tese de Doutorado, Campinas, Universidade Estadual de Campinas.

Souza, V.C. \& Lorenzi, H. 2005. Botânica Sistemática: Guia Ilustrado para identificação das famílias de Angiospermas da flora brasileira, baseado em APG II. Nova Odessa, Instituto Plantarum.

van den Berg, E. \& Oliveira Filho, A.T. 2000. Composição florística e estrutura fitossociologica de uma floresta ripária em Itutinga, MG, e comparação com outras áreas. Revista Brasileira de Botânica 23: 231-253.

van Tongeren, O.F.R. 1995. Cluster analysis. Pp. 174-212. In: R.H.G. Jongman; C.J.F. Ter Braak \& O.F.R. van Tongeren. Data analysis in community and landscape ecology. Cambridge, University Press. 